\title{
THERMALLY ASSISTED TUNNELING: AN ALTERNATIVE MODEL FOR THE THERMOLUMINESCENCE PROCESS IN CALCITE
}

\author{
J. F. de Lima ${ }^{\dagger}$, M. E. G. Valerio ${ }^{\dagger}$ and E. Okuno \\ ${ }^{\dagger}$ Depto de Física, Universidade Federal de Sergipe, \\ 49.100-000, S. Cristóvão-SE, Brazil, \\ e-mail: lima@ufs.bror mvalerio@ufs.br \\ ${ }^{\ddagger}$ Instituto de Física, Universidade de São Paulo, CP 66.318, \\ 05315-970, S. Paulo, Brazil
}

(July 11, 2021)

\begin{abstract}
In this work we investigate the effect of gamma and ultraviolet radiations on the thermoluminescence of Brazilian calcite. The irradiated samples presented three TL peaks at 150, 245 and $320^{\circ} \mathrm{C}$ (at a linear heating rate of $\left.1.8^{\circ} \mathrm{C} / \mathrm{s}\right)$, with a main emission band centered at $615 \mathrm{~nm}$ due to the ${ }^{4} G \rightarrow{ }^{6} S$ transition of the $\mathrm{Mn}^{2+}$. The irradiated samples presented, besides the $\mathrm{Mn}^{2+}$ signals, three lines related related to carbonate groups. The thermal treatment and the irradiation effects on the ESR signal lead to the conclusion that $\left(\mathrm{CO}_{3}\right)^{3-}$, stabilized in two different symmetries, and the $\left(\mathrm{CO}_{2}\right)^{-}$ions are the electron trapping centers. It was found that the TL peaks follows a $t^{-1}$ decay as a function of the $U V$ illumination time. An alternative model for the TL emission of calcite is discussed, considering that the recombination of charges is processed via a thermally assisted tunnelling mechanism.
\end{abstract}

\section{INTRODUCTION}

Calcite is a mineral found in many geological formations. Its thermoluminescence (TL) has been studied, mainly due to its application in geological and fossil dating [1] 3]. Calcite can also be used for ionizing and ultraviolet radiation dosimetry.

Investigations on calcite have shown different TL characteristics depending on the impurity content and on the genesis of the sample. It was also observed on artificially grown $\mathrm{CaCO}_{3}$ crystals that the type and concentration of impurities modify both TL sensitivity and glow curve shape.

Important contributions have been made to the understanding of the TL mechanism of calcite since the pioneering works of Kolbe and Smakula [4 and Medlin [5] in the sixties. Studying the influence of manganese concentration, and by comparison of the emission spectrum of calcite with the emission of the others lattices including manganese, Medlin found that the emission band centered in $615 \mathrm{~nm}$, corresponding to a transition from the first excited to the fundamental state of $\mathrm{Mn}^{2+}$ ion occupying a $\mathrm{Ca}^{2+}$ site. Recent works [6,7] showed that the shape of the emission spectrum changes from a broad band without structure to a well-resolved narrow band when the temperature of the TL peak increases and when the concentration of the Mn decrease. They also concluded that the orange emission is related to Mn impurity. Calderon at al [8] suggested that the holes are trapped by the impurities and electrons are trapped at dislocations forming $\left(\mathrm{CO}_{3}\right)^{3-}$. The irradiation with UV light was found to modify the intensity of the TL peaks suggesting that the trapped carriers can be phototransfered from deep to shallow traps [9]. Concerning the kinetics of the detrapping process, it was found that the isothermal decay follow a $\mathrm{t}^{-1}$ law which could not be accounted for a single trap model. Many workers explained this results assuming that the process are due to a distribution in the activation energies 13 15. On the other hand, Visocekas et al [10] suggested that, for the peaks observed on their samples below room temperature, this behavior could be due to a tunnelling process.

In the present work we investigate the effect of gamma and ultraviolet radiations on the thermoluminescence of Brazilian calcite from Miranda, MS. Based on a correlation between TL and electron spin resonance (ESR) and on the photoinduced TL decay, we suggest an explanation for the appearance of the three peaks between room temperature and $450^{\circ} \mathrm{C}$, and propose an alternative model for the thermoluminescence process.

\section{EXPERIMENTAL}

Brazilian calcite from Miranda, MS used in this work was powdered and sieved and the grains with diameters between $74 \mu \mathrm{m}$ and $174 \mu \mathrm{m}$ were selected. Chemical analysis by atomic absorption and X-ray fluorescent spectroscopy techniques detected the following impurities: $\mathrm{Si}(<0.1 \%), \mathrm{Al}(<0.1 \%), \mathrm{Fe}(<0.05 \%), \operatorname{Ti}(<0.05 \%)$, $\mathrm{Mg}(<0.23 \%), \mathrm{Na}(<0.03 \%)$ and $\mathrm{K}(<0.05 \%)$. Electron spin resonance measurements revealed the presence of manganese. Samples were exposed to ${ }^{60} \mathrm{Co}$ gamma rays from 50Gy to 500Gy. Ultraviolet irradiation was performed at a distance of $0.5 \mathrm{~m}$ from a high pressure $400 \mathrm{~W}$ mercury lamp. A home made TL reader was used to heat 
$4 \mathrm{mg}$ powder samples from $30^{\circ} \mathrm{C}$ to $400^{\circ} \mathrm{C}$ in a nitrogen atmosphere, at a heating rate between $1^{\circ} \mathrm{C} / \mathrm{s}$ to $3^{\circ} \mathrm{C} / \mathrm{s}$. We performed a series of monochromatic TL measurements with wavelength varying from 450 to $750 \mathrm{~nm}$ in steps of $10 \mathrm{~nm}$. Data were stored in a microcomputer and the $3 \mathrm{D}$ isometric plots were constructed via software after correcting each of monochromatic curves to the wavelength response of the system.

ESR experiments were performed with a BRUKER ER 200D equipment, also on powdered samples at room temperature, in the X-band and $1.0 \mathrm{~mW}$ microwave power (below saturation). The peak to peak height of the first derivative of the signal was considered to be proportional to the number of paramagnetic centres.

\section{RESULTS}

The glow curve of untreated sample (without any treatment in laboratory) consists of two peaks at 245 and $320^{\circ} \mathrm{C}$ when heated at a rate of $1.8^{\circ} \mathrm{C} / \mathrm{s}$. After a laboratory dose of gamma rays, the intensity of these peaks increases and another peak, around $150^{\circ} \mathrm{C}$, appears. Hence for simplicity these peaks are labeled as peaks A, B, and $\mathrm{C}$ as their temperatures increase.

Figure 1 shows the isometric plot and the contour plot of the TL spectra of the irradiated samples. The three main peaks present a broad emission band centered at $615 \mathrm{~nm}$. Besides this band, peaks A and B present a very weak emission band at 480nm, not usually reported. Comparing the TL spectra around $615 \mathrm{~nm}$ at the peak temperatures we can see that peak $\mathrm{C}$ displays a finestructure with at least 4 emission lines in this region while peak $\mathrm{A}$ are mainly composed by the main emission at $615 \mathrm{~nm}$. These results agree with previous results [6,7]. Treated samples (with a heat treatment at $400^{\circ} \mathrm{C}$ for 1 hour followed by a gamma irradiation) show a similar glow curve, without changes in the peak positions.

The growth and the saturation of the peak heights with the exposure to gamma rays are shown in figure 2 . The effect of post-irradiated thermal treatment at different temperatures shows that the decrease of TL intensity is accompanied by the dislocation of the TL peak maxima to higher temperatures indicating that the TL processes can not be accounted for a first order kinetic. Figure 3 shows the effect of $10 \mathrm{~min}$ post-irradiation annealing at different temperatures. We can see that as the temperature of post-irradiation thermal treatment increases, the intensity of the TL peaks decrease. Peak A vanish first followed by peak B and finally by peak C.

The effect of ultraviolet (UV) irradiation on the thermoluminescent properties was studied using both untreated (without any treatment in the laboratory) and treated samples (with a heat treatment at $400^{\circ} \mathrm{C}$ for 1 hour followed by gamma irradiation). When treated samples are irradiated with UV all the three peaks decrease and the peak maxima shift to higher temperatures (Fig- ure 4), a similar shifts is produced by thermal bleaching. To check if any isothermal reduction of the peak was happening during the UV illumination, the temperature of the samples was monitored. We found that during the $\mathrm{UV}$ illumination the temperature is around $30^{\circ} \mathrm{C}$. Measurements of the isothermal decay of the TL peaks revealed that, considering the time intervals used in these experiments, the isothermal decay at this temperature can be neglected. Figure 5 shows the variation of the inverse of TL intensity as a function of the illumination time "t $"$ where we can see that TL intensity of the three peaks are proportional to $\mathrm{t}^{-1}$.

In figure 6 we show the result of the intensities of the ESR signals as a function of the radiation dose. The ESR measurements were performed at room temperature and it is possible to see that increasing the gamma ray doses, the well known signals of the $\mathrm{Mn}^{2+}$ ion present in the samples decrease. At the same time three other signals labelled 2, 3 and 5 , with $\mathrm{g}_{2}=2.0036, \mathrm{~g}_{3}=2.0032$, and $g_{5}=2.0006$ typical of free radicals, increase. The effect of the post-irradiation thermal treatment at different temperatures during 10 minutes on the labeled ESR signals are shown in figure 7 . The increase of temperature of post irradiation heat treatments causes the increase of the $\mathrm{Mn}^{2+}$ signal and decrease firstly of the signal 3, at the $75-150^{\circ} \mathrm{C}$ range, followed by the signal 2 , at 200$350^{\circ} \mathrm{C}$, and finally the signal 5 , starting at $280^{\circ} \mathrm{C}$ (Figure 7). Thermal treatment at $400^{\circ} \mathrm{C}$ during 1 hour eliminate all the 2, 3 and 5 signals produced by the irradiation.

\section{DISCUSSION}

At present, the plain understanding of thermoluminescent emission requires the identification of the luminescence and the trapping centers and the indication of the charge carrier transference and recombination processes. The results presented on this work allow us to confirm the explanation presented by other researches and point out an alternative model to the charge carrier transference.

From figure 1 we can see that the three peaks have the same emission band centered on $615 \mathrm{~nm}$. This result combined with the result that the ESR signal related to $\mathrm{Mn}^{2+}$ decrease with the irradiation dose and is recovered if the sample is heated, (see figures 6 and 7), clearly establish that the $\mathrm{Mn}$ is the hole trap formed upon irradiating the crystal and that during the heating it is both the recombination and the luminescence center. These results agree with the results found by other authors [6,7] that pointed out that the emission band centered in $615 \mathrm{~nm}$ is due to the ${ }^{4} \mathrm{G} \rightarrow{ }^{6} \mathrm{~S}$ transition of the $\mathrm{Mn}^{2+}$ ion.

ESR signals $3\left(g_{3}=2.0036\right), 2\left(g_{2}=2.0032\right)$ have been associated 11] to the $\left(\mathrm{CO}_{3}\right)^{3-}$ while signal $5\left(\mathrm{~g}_{5}=\right.$ $2.0006)$ is associated with $\left(\mathrm{CO}_{2}\right)^{-}$. In our experiments signals 3 and 2 bleach at different temperature ranges suggesting two different types of $\left(\mathrm{CO}_{3}\right)^{3-}$ on the crystal lattice. The decay of the free radical ESR signals with 
increasing heat treatment temperature points out to an unambiguous correlation between the A, B and C TL peaks and 3, 2 and 5 ESR signals. From this result, combined with the growth of these signal as a function of the radiation dose described in figure 6 , we can conclude that the $\left(\mathrm{CO}_{3}\right)^{3-}$ and the $\left(\mathrm{CO}_{2}\right)^{-}$are the electron trapping centers.

The results presented by Medlin [13,14 showed that the isothermal decay of the phosphorescence of calcite crystals follows a $\mathrm{t}^{-1}$ law. Medlin [13] and Pagonis et al [15] attributed this behavior to a recombination processes with a distribution in the energies of the electron traps.

The $\mathrm{T}_{m} \mathrm{xT}_{\text {stop }}$ method, initially proposed by McKeever [3] as a tool for distinguishing among different kinetics and mechanisms, was performed in natural calcite by Lima et al [16]. Their results clearly indicated that the distribution in activation energies can not account for the TL peaks in calcite.

In the present work UV light was used to release the trapped electrons and generates the electron-hole recombination process (figures 4 and 5). The results obtained from these measurements show that the decay of the gamma-ray induced TL peaks due to exposure to UV light is inversely proportional to the illumination time, as we can see from figure 5 .

The detrapping rate, in this experiment, is proportional to the intensity of the UV light but the mechanism of the charge recombination and the light emission should be the same if we employed thermal activation. In the former, a distribution of traps can not explain the $\mathrm{t}^{-1}$ law also observed.

Taking into account all these results we are proposing that the charge transfer mechanism is processed via a thermally assisted tunnelling from the carbonate groups, as described earlier, and the $\mathrm{Mn}^{3+}$. This process can explain the decay of the TL peak intensity with the UV illumination time, found in the present work, the isothermal decay of the phosphorescence in calcite, found by Medlin and Pagonis et al., and the $\mathrm{T}_{m} \times \mathrm{T}_{\text {stop }}$ results, found by Lima et al. This proposal is also in agreement with the observation that the TL peaks in calcite are not accompanied by any thermally stimulated conductivity peaks, as it was showed by Medlin [17], and that the emission of light during the recombination process is generated in a "localized-type" mechanism [18.

If the recombination of charges between the electron and the hole traps are via a tunnelling process, both centers should be close enough to enable the tunnelling process to take place. Hence, we suggest that during the irradiation of the samples the $\left(\mathrm{CO}_{3}\right)^{3-}$ and $\left(\mathrm{CO}_{2}\right)^{-}$ centers are formed in the vicinity of a $\mathrm{Mn}^{2+}$ substituting for a $\mathrm{Ca}^{2+}$ of the calcite matrix. The two different $\left(\mathrm{CO}_{3}\right)^{3-}$ observed in the ESR measurements can be attributed to carbonate groups at nearest-neighbor and at next-nearest-neighbor positions of the Mn dopant.

\section{CONCLUSION}

In conclusion, the results observed in the present work clearly establish the role of the $\left(\mathrm{CO}_{3}\right)^{3-}$ and $\left(\mathrm{CO}_{2}\right)^{-}$ ions as the main trapping centres and the role of the $\mathrm{Mn}^{2+}$ as the recombination and the luminescence centre in the TL processes in calcite. The observed TL peaks can be explained as follows: during irradiation, $\mathrm{Mn}^{2+}$ ions change to $\mathrm{Mn}^{3+}$, losing one electron that is captured in a $\left(\mathrm{CO}_{3}\right)^{2-}$, forming the $\left(\mathrm{CO}_{3}\right)^{3-}$ ion or the $\left(\mathrm{CO}_{2}\right)^{-}$ ion. The $\left(\mathrm{CO}_{3}\right)^{3-}$ can be formed either in a nn or in a nnn position to the $\mathrm{Mn}^{3+}$ dopant generating two different $\left(\mathrm{CO}_{3}\right)^{3-}$ ions. Upon heating, the electron recombines with the hole left in the $\mathrm{Mn}^{3+}$, after a thermally assisted tunnelling from a trap close to the manganese. The resulting $\mathrm{Mn}^{2+}$ is formed in an excited state, whose decay is responsible for the emitted light during the TL process.

[1] M. J. Aitken, Thermoluminescence Dating. (Academic Press, London, 1985).

[2] D. J. McDougall (editor), Thermoluminescence of Geological Materials. (Academic Press, London, 1968).

[3] S. W. S. McKeever, Thermoluminescence of Solids. (Cambridge University Press, Cambridge 1985)

[4] W. F. Kolbe and A. Smakula, Phys. Rev. 124, 1754 (1965).

[5] W. L. Medlin, "The nature of traps and emission centers in thermoluminescent rock materials ", in Thermoluminescence of Geological Materials, Editor: D. J. McDougall (Academic Press, London, 1968).

[6] J.S.Down, R.Flower, J.A.Strain, and P.D.Townsend, Nucl. Tracks. 10, 581, (1985).

[7] T. Calderon, P. D. Townsend, P. Beneitez, J. GarciaGuinea, A.Millán, H. M. Rendell, A. Tookey, M. Urbina and R. A. Wood, Radiat. Meas. 26, 719 (1996).

[8] T. Calderon, M. Aguilar, F. Jaque and R. Coy-yll, J. Phys. C 17, 2027 (1984).

[9] J. F. Lima, P. Trzesniak, E. M. Yoshimura, and E. Okuno, Radiat. Prot. Dosim. 33, 143 (1990).

[10] R.Visocekas, T.Ceva, C.Marti, F.Lefaucheux, and M.C.Robert, Phys. Stat. Sol. A35, p315-327, (1976).

[11] S. A. Marshall, J. A. McMillan and S. V. Nistor, J. Magn. Reson. 14, 20 (1974).

[12] P. Avouris and T.N. Morgan, J. Chem. Phys. 74, 4347 (1981)

[13] W. L. Medlin, Phys. Rev. 122, 837 (1961)

[14] W. L. Medlin, Phys. Rev. 123, 502 (1961)

[15] V. P. Pagonis, E. Allman and A. Wooten Jr., Rad. Meas. 26, 265 (1996)

[16] J F de Lima, E M Yoshimura and E Okuno, Nucl. Instrum. Methods A280, 436 (1989)

[17] W. L. Medlin, Phys. Rev. 135, A1770 (1964)

[18] W. L. Medlin, J. Chem. Phys. 30, 451 (1959) 
FIG. 1. Isometric(a) and contour (b) plots of thermoluminescent spectra of a gamma-ray irradiated Brazilian calcite, recorded at $1.8 \mathrm{oC} / \mathrm{s}$.

FIG. 2. TL peak heights of Brazilian calcite as a function of exposure to gamma-rays.

FIG. 3. Decay of TL intensity with annealing temperature during $10 \mathrm{~min}$ of calcite previously irradiated with a laboratory dose of gamma-rays.

FIG. 4. Glow curve of calcite previously exposed to gamma-rays and illuminated with UV during 5 and $10 \mathrm{~min}$. A glow curve without UV illumination is also shown.

FIG. 5. Reciprocal of the TL peak heights of thermally treated calcite as a function of UV exposure time.

FIG. 6. Intensity of ESR signals of a Brazilian calcite sample as a function of exposure to gamma-rays.

FIG. 7. Effect of the annealing temperature for $10 \mathrm{~min}$ in the ESR signals of calcite irradiated with gamma-rays. 
(a)

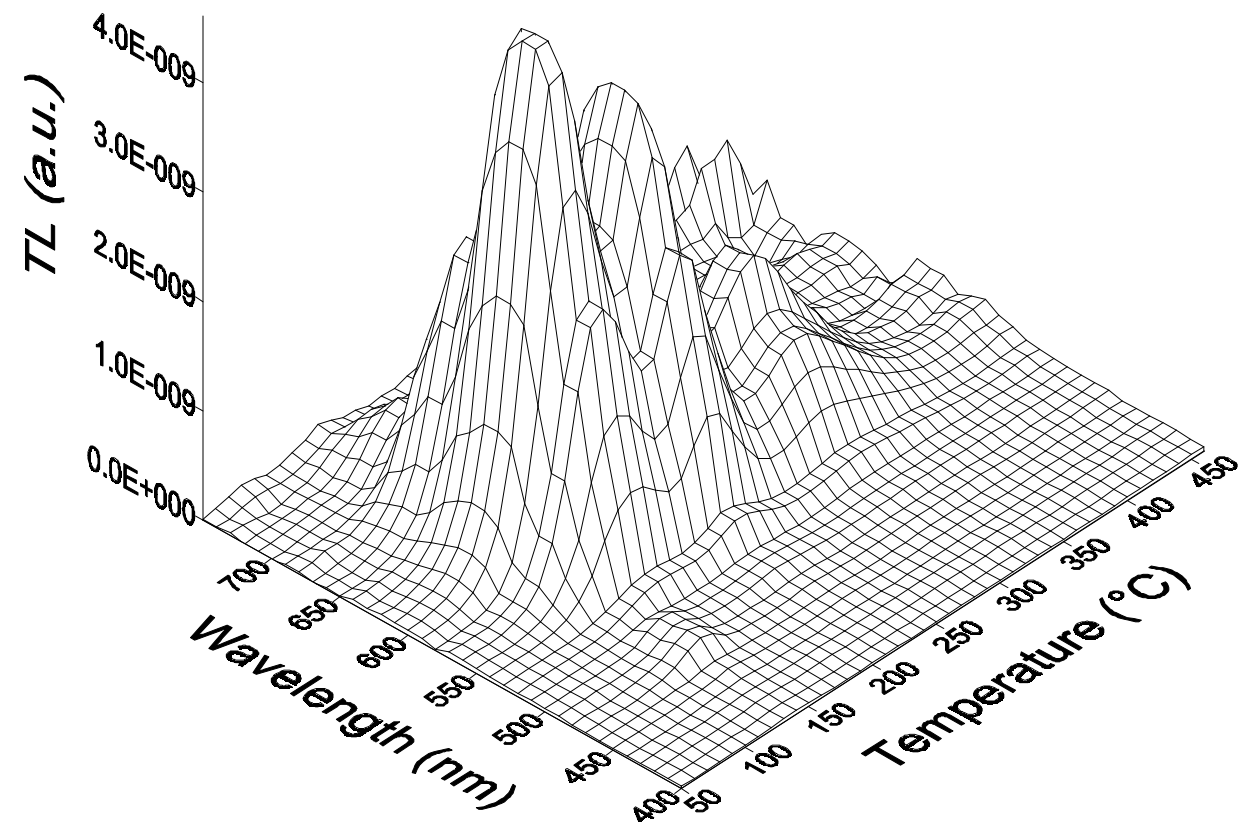

(b)

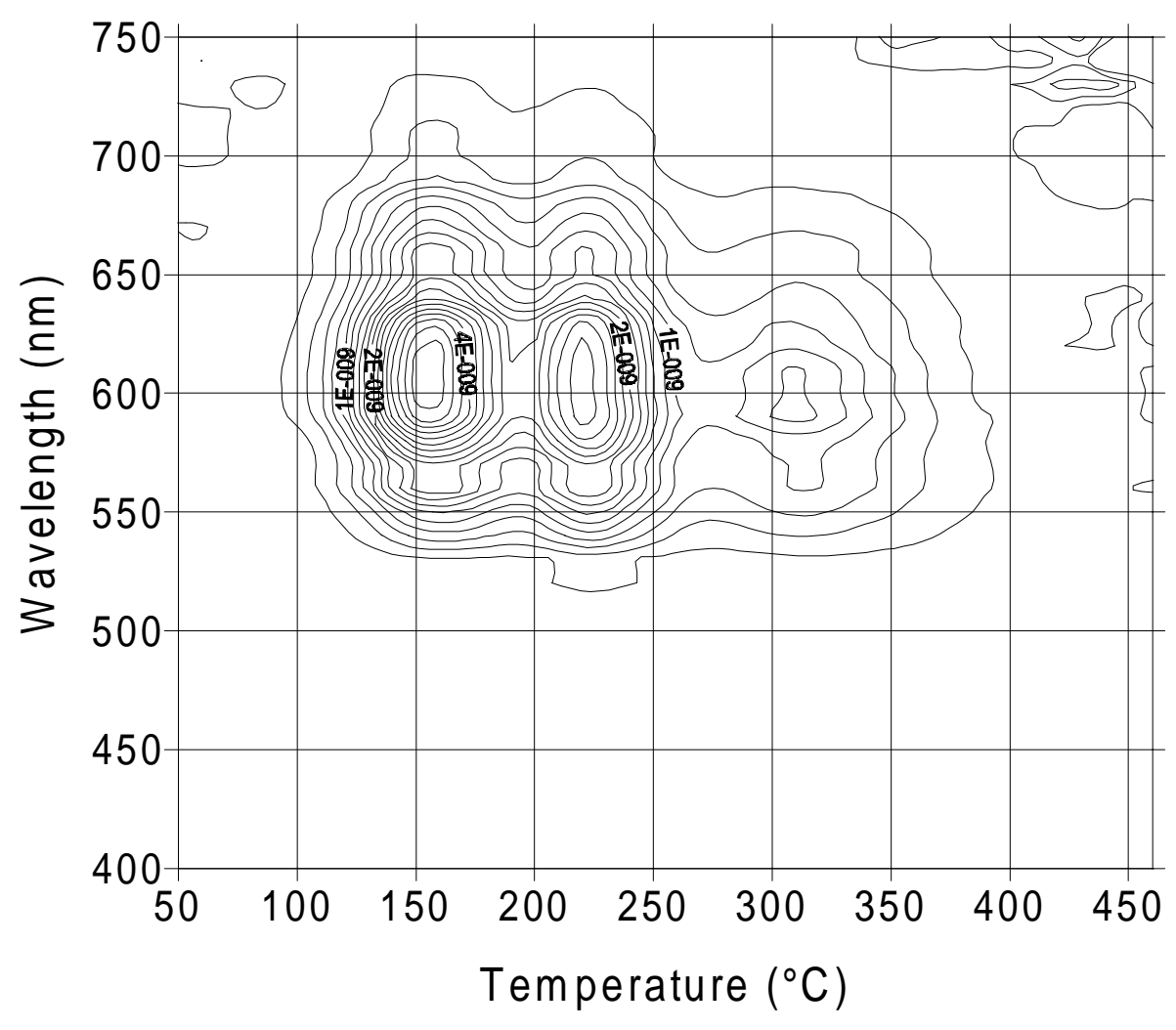




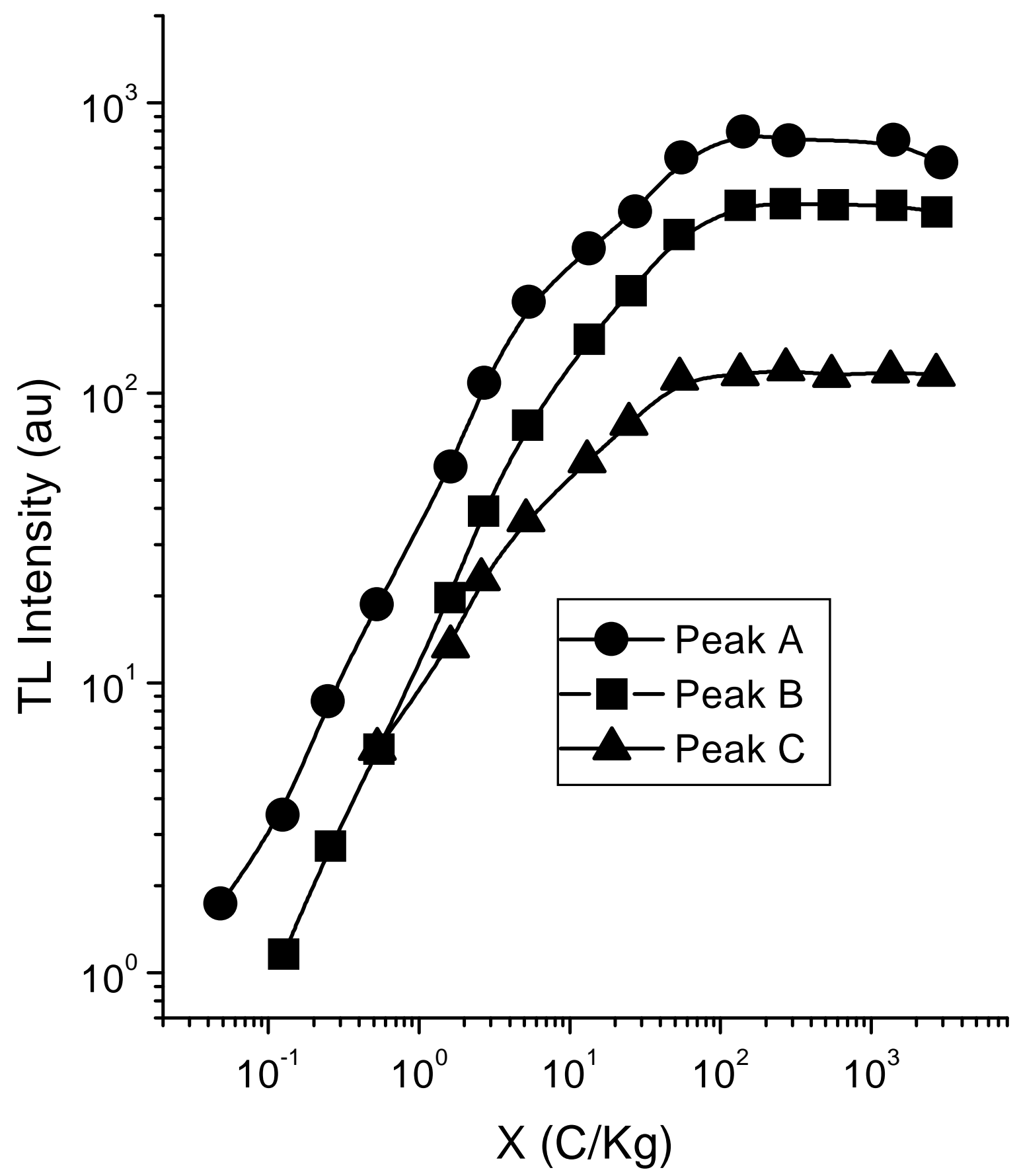




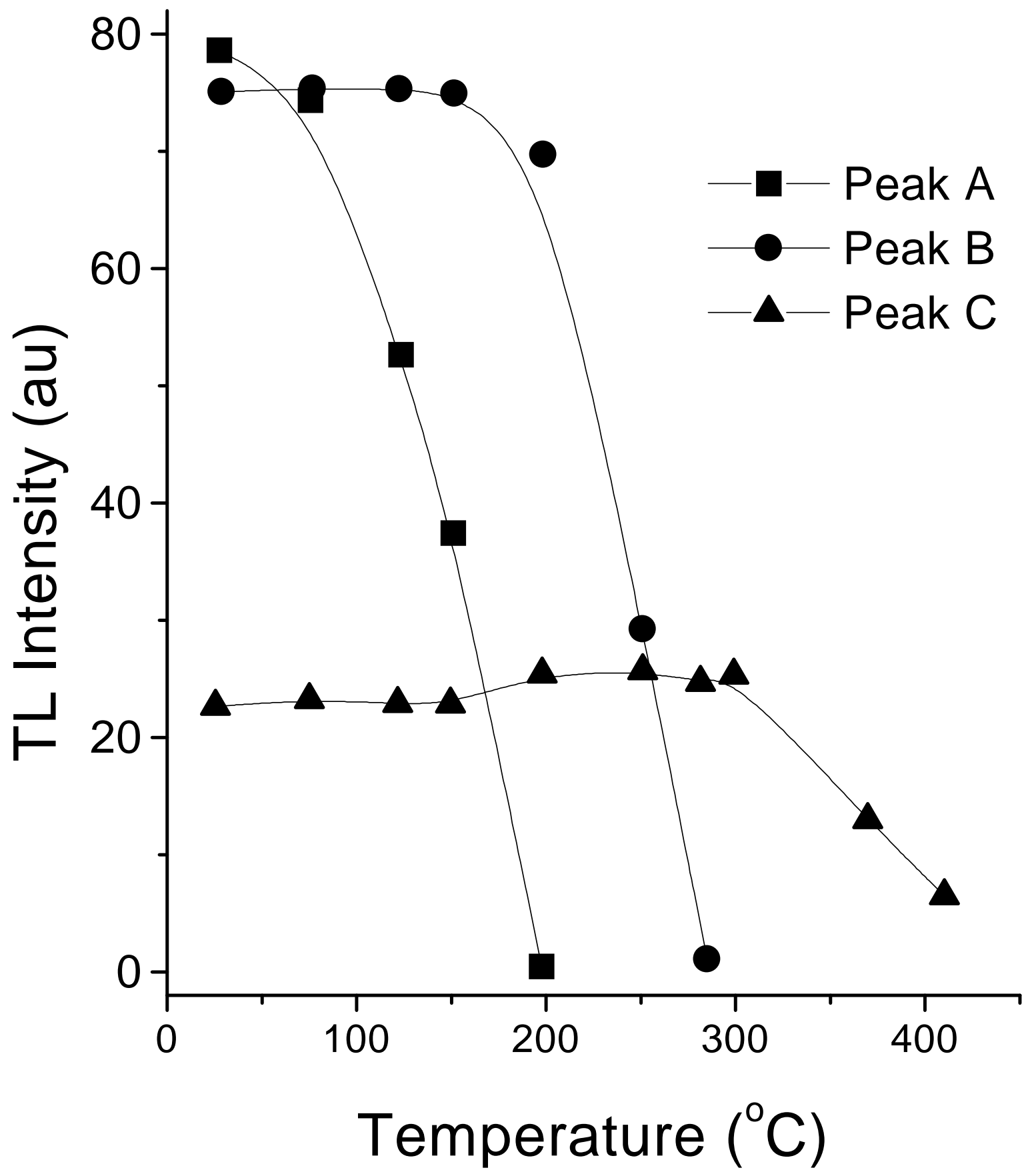




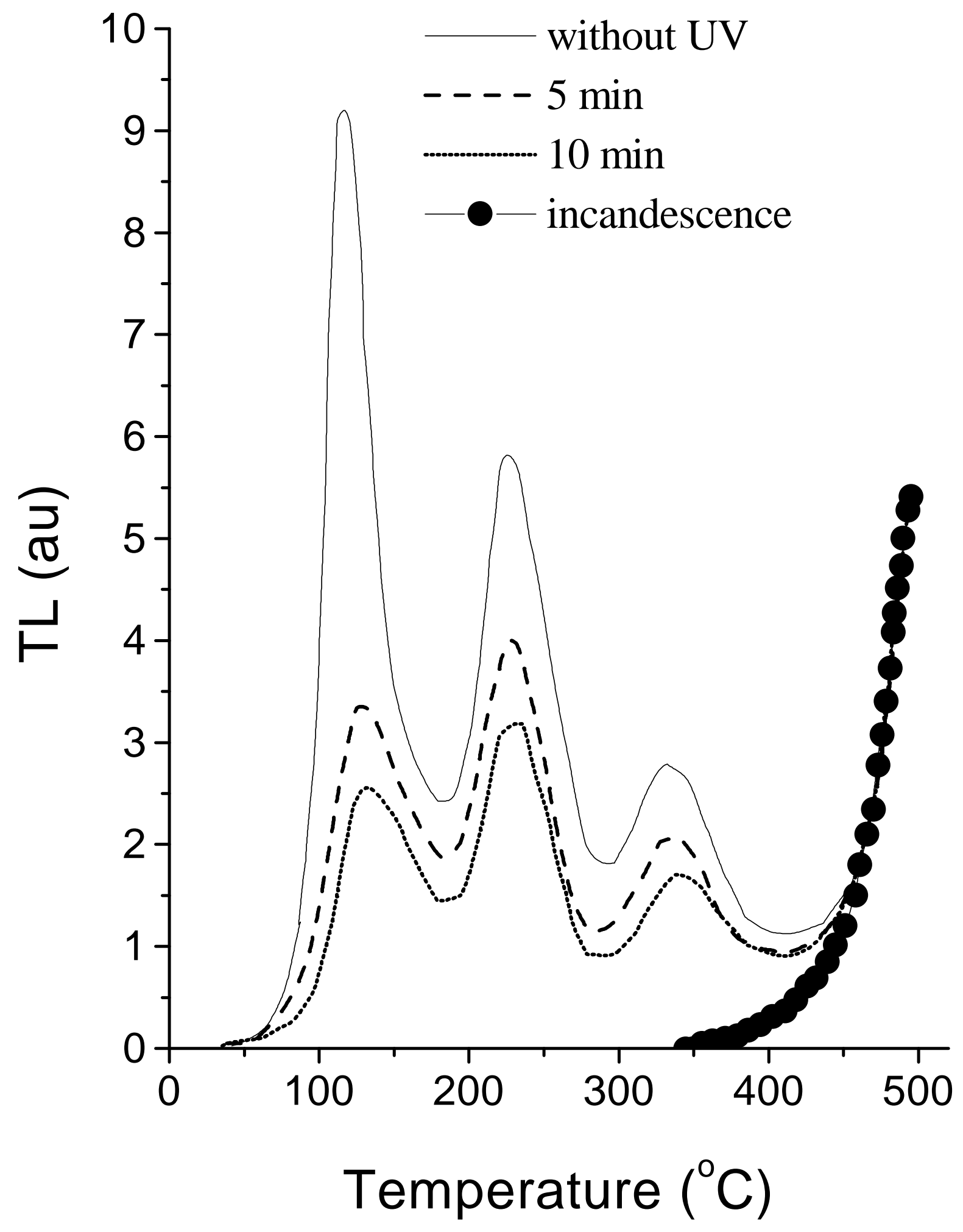




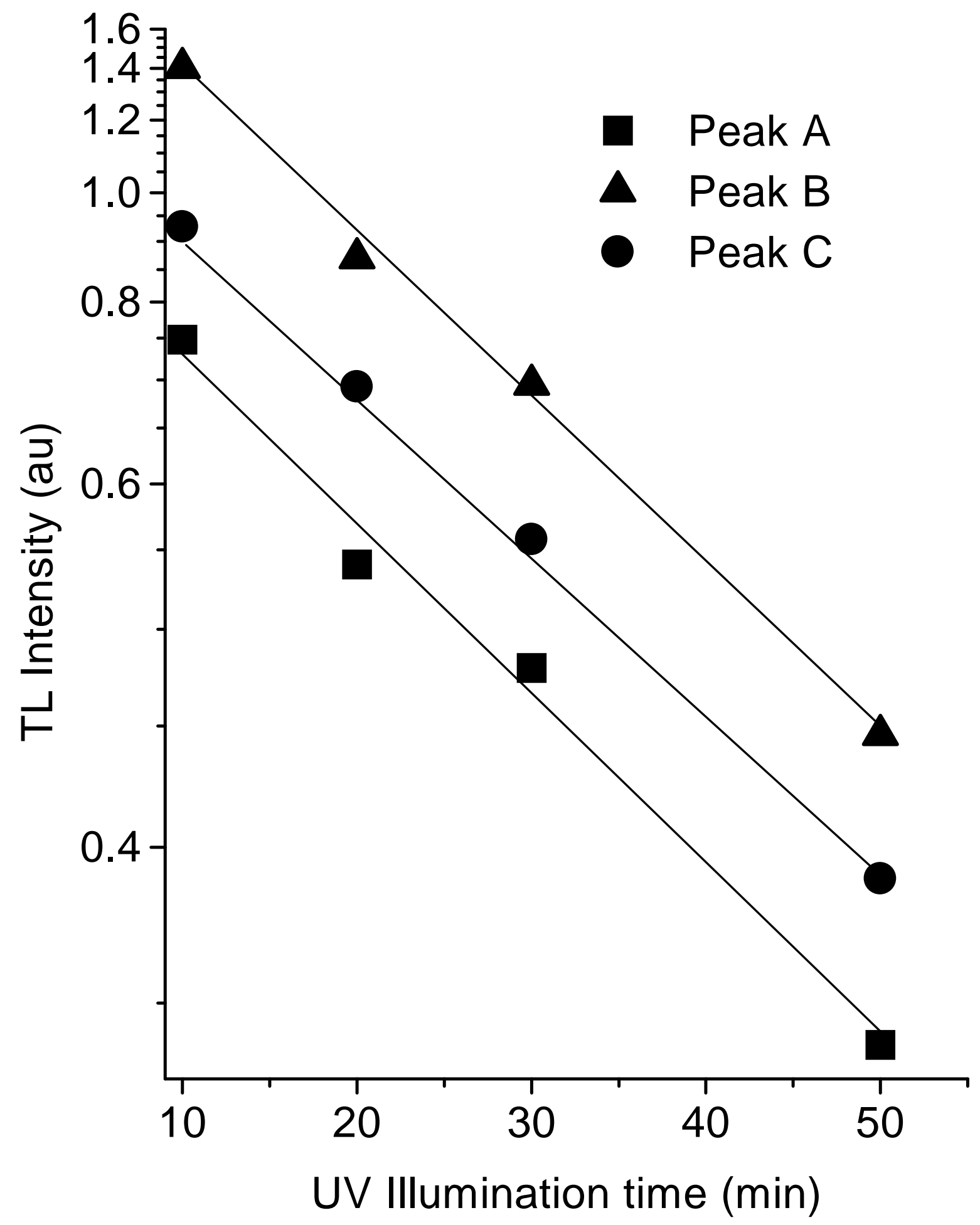




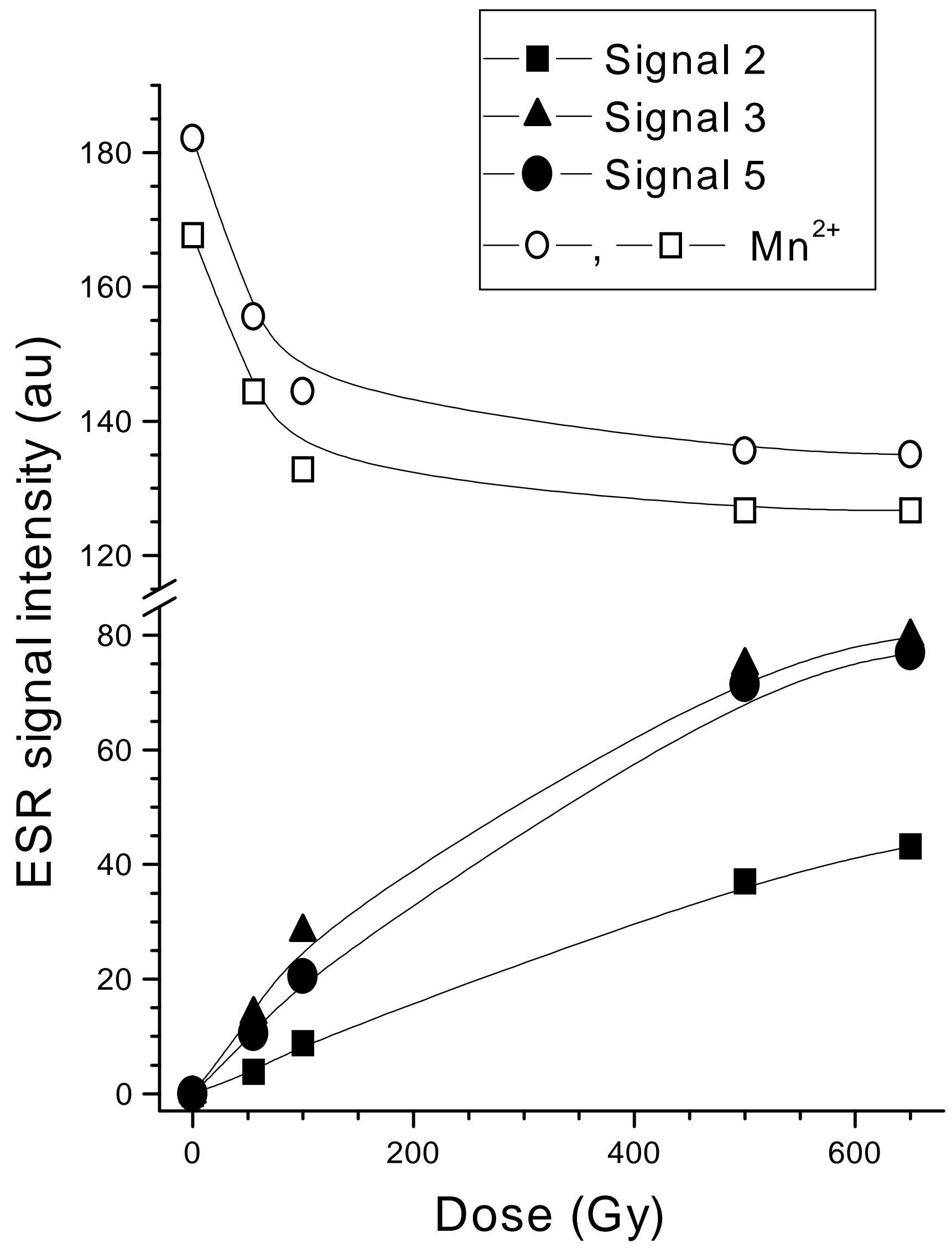




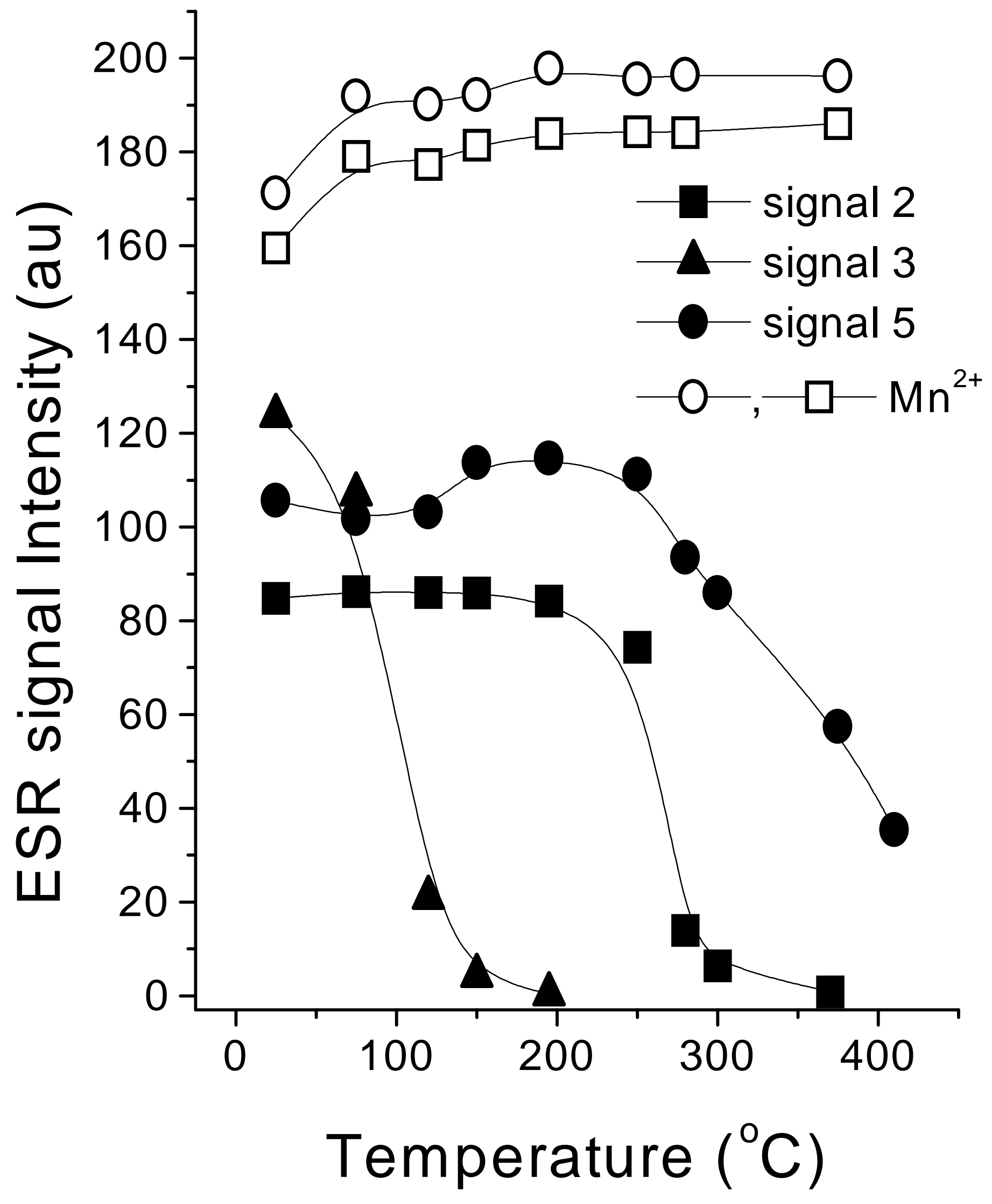

